\title{
Cardiac Catheterization Under Echocardiographic Control in a Pregnant Woman
}

\author{
RICHARD S. MELTZER, M.D.* \\ PATRICK W. SERRUYS, M.D. \\ JACKIE MCGHIE \\ PAUL G. HUGENHOLTZ, M.D. \\ JOS ROELANDT, M.D. \\ Rotterdam The Netherlands
}

From the Thoraxcenter, Erasmus University and Academic Hospital Dijkzigt, Rotterdam, The Netherlands. This work was supported in part by grants from the Dutch Heart Foundation and the Interuniversity Cardiology Institute. Requests for reprints should be addressed to Dr. Richard S. Meltzer, Thoraxcenter, Erasmus University, Post box 1738, 3000 DR Rotterdam, The Netherlands.

- Clinician-Scientist of the American Heart Association.

\begin{abstract}
A 22 year old woman had signs of rheumatic mitral and aortic valve disease early in pregnancy. Cardiac catheterization was performed during her third month of pregnancy under two-dimensional echocardiographic control without the use of ionizing radiation. Severe mitral stenosis with mild aortic stenosis was found. Five cubic centimeters of 5 percent dextrose in water were injected by hand to obtain left ventriculograms and supravalvular aortograms of sufficient quality to diagnose valvular regurgitation. The use of "echo-catheterization" may have significant advantages in selected clinical situations.
\end{abstract}

There is a strong contraindication to the use of ionizing radiation during the early stages of pregnancy due to its known teratogenic effects [1]. Indeed, avoidance of ionizing radiation to the gonads is desirable for any woman in the reproductive age range. Young women with cardiac disease who become pregnant face a possible worsening of their hemodynamic functions later in pregnancy due to increased cardiac demands during the third trimester [2,3]. Thus, when a physician is asked to evaluate such a situation in order to decide if an operation will be necessary to prevent hemodynamic deterioration later in pregnancy, he is presented with a dilemma. Cardiac catheterization is frequently necessary to obtain precise information on which to base operative recommendation. When recently confronted with this problem we decided to attempt catheterization entirely under twodimensional echocardiographic control.

\section{CASE REPORT}

A 22 year old woman was admitted to the Thoraxcenter in the second month of pregnancy. During the year before examination she noted gradually increasing fatigue and dyspnea on exertion. She denied having orthopnea, palpitation or precordial pain; she was able to do her housework with difficulty and was judged to be in New York Heart Association Class III functional capacity. On physical examination the patient appeared healthy. Blood pressure was $100 / 60 \mathrm{~mm} \mathrm{Hg}$ and pulse rate 100 beats/min and regular. The carotid upstroke was mildly slowed. There was a diastolic apical trill. The first heart sound was increased in intensity, the second was normal, followed by an opening snap and a loud diastolic rumble. There was a grade $3 / 6$ ejection murmur at the upper right sternal border, and a soft early diastolic decrescendo murmur at the lower left sternal border. The liver was not enlarged, and there was no peripheral edema.

The electrocardiogram revealed sinus tachycardia at a rate of $110 / \mathrm{min}$, left atrial enlargement and no signs of left ventricular hypertrophy. Chest film showed left atrial enlargement and a normal-sized heart. M-mode echocardiogram gave a classic picture of rheumatic mitral stenosis with a mildly di- 

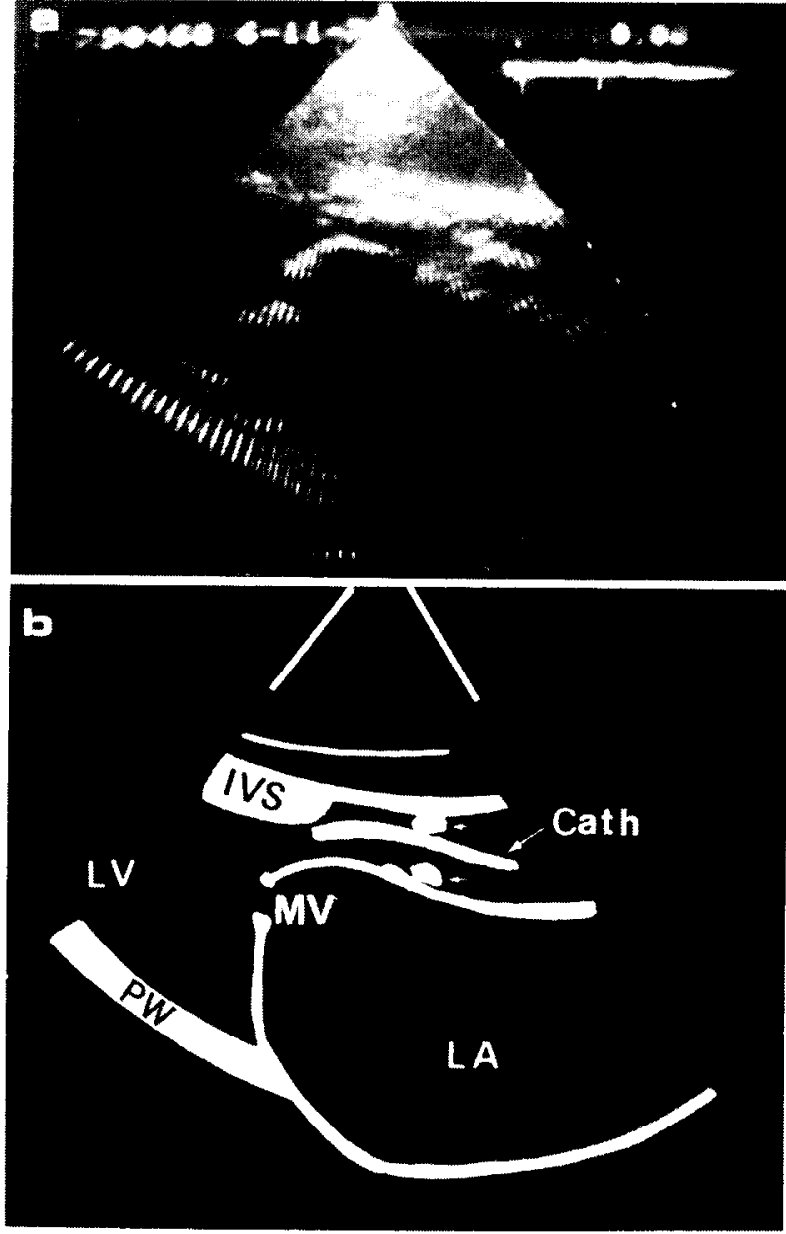

Figure 1. a, stop frame image from the two-dimensional echocardiographic study; left parasternal long axis view. The catheter has crossed the aortic valve. $\mathbf{b}$, diagram of panel a. IVS = interventricular septum; $L V=$ left ventricle; Cath $=$ catheter $M V=$ mitral valve; $P W=$ left ventricular posterior wall; $L A=$ left atrium. The two small arrows indicate thickened aortic valve cusps.

lated left atrium and increased aortic valve echoes suggesting rheumatic involvement. Two-dimensional study confirmed this and suggested the presence of moderate mitral stenosis with a fairly flexible, noncalcified valve. Mitral valve area planimetered directly from the short axis two-dimensional echocardiographic view was $0.9 \mathrm{~cm}^{2}$. The aortic valve gave increased echoes with a mild reduction in opening amplitude. The carotid curve showed an ejection time of 0.30 second with a "shudder" near the top and suggested mild aortic stenosis.

The diagnosis of combined mitral and aortic stenosis of rheumatic origin was made. In order to decide if the patient would need an operation during her pregnancy, and to measure the aortic valve gradient, she was catheterized during her third month of pregnancy. Right-sided heart and pulmonary wedge pressures were obtained using a balloon flotation catheter positioned under pressure guidance alone. Attempts at retrograde catheterization of the left ventricle under electrocardiographic guidance alone, using a 3 French
Grandjean catheter [4], were unsuccessful due to the inability to pass the aortic valve. After 5 minutes, these attempts were stopped. From this point on a Toshiba SSH-10A two-dimensional phased array ultrasonograph was used to monitor the catheter position and to guide its manipulation. No fluoroscopy was employed. A No. 5 French Lehman ventriculography catheter was introduced into the aortic root from the right brachial artery and was easily imaged by two-dimensional echocardiography with the patient in a slight left lateral decubitus position on the catheterization table. Unlike the Grandjean catheter, the Lehman catheter cannot be used for "blind" aortic valve probing under electrocardiographic or pressure guidance because of the danger of inadvertent coronary artery catheterization. The parasternal long axis view was used during aortic valve crossing. The catheter crossed the aortic valve after 3 minutes of probing. Figure 1 is a stop action frame from the video recording which shows the catheter across the aortic valve. Although not calcified, the thickened aortic valve leaflets could be easily seen. Continuous visualization of the cusps throughout systole and diastole facilitated attempts to pass the aortic valve. When the catheter was first visualized in the aortic root it was slowly advanced, but the image of the tip did not seem to advance as expected. The catheter was, therefore, partially withdrawn and the parasternal long axis echocardiographic plane slightly altered. During the following attempt, the catheter tip image seemed to advance and withdraw appropriately as the catheter was manipulated. It was, therefore, advanced to just above the cusps; as the aortic valve opened during systole, it was advanced across the valve with left ventricular diastolic pressure noted on the following diastole. An echocardiographic left ventriculogram was obtained (Figure 2) using 5 $\mathrm{ml}$ of 5 percent dextrose in water which was injected by hand. It confirmed a normal ventricular contraction pattern, no significant mitral regurgitation and clear visualization of "negative contrast" in the left ventricle due to the jet of unopacified left atrial blood which entered during diastole. Several echocardiographic supravalvular aortograms were obtained after pull-back across the aortic valve. The aortograms were performed to discern whether the diastolic murmur was of aortic or pulmonic origin. Each injection employed 5 to $10 \mathrm{cc}$ of 5 percent dextrose in water and yielded adequate opacification of the aortic root. A still frame from one injection is shown in Figure 3. Left ventricular contrast due to aortic regurgitation is seen. Hemodynamic studies showed a cardiac index of 2.9 liters $/ \mathrm{min}$, a mean mitral valve gradient of $25 \mathrm{~mm} \mathrm{Hg}$ with a calculated area of $1.0 \mathrm{~cm}^{2}$. The mean aortic valve gradient was $31 \mathrm{~mm} \mathrm{Hg}$ and the calculated area $0.9 \mathrm{~cm}^{2}$ (uncorrected for aortic regurgitation). Pulmonary artery pressure with the patient at rest was $95 / 42 \mathrm{~mm} \mathrm{Hg}$ with a mean pressure of $61 \mathrm{~mm} \mathrm{Hg}$.

The patient underwent mitral commissurotomy at the end of her fourth month of pregnancy. No mitral regurgitation was noted on left atrial palpitation, and a closed commissurotomy was performed. Her postoperative course was uneventful. Right-sided catheterization showed a mean wedge pressure of $9 \mathrm{~mm} \mathrm{Hg}$ on the 10th postoperative day.

\section{COMMENTS}

The ability to perform an entire diagnostic catheterization in this patient without fluoroscopy was a major 

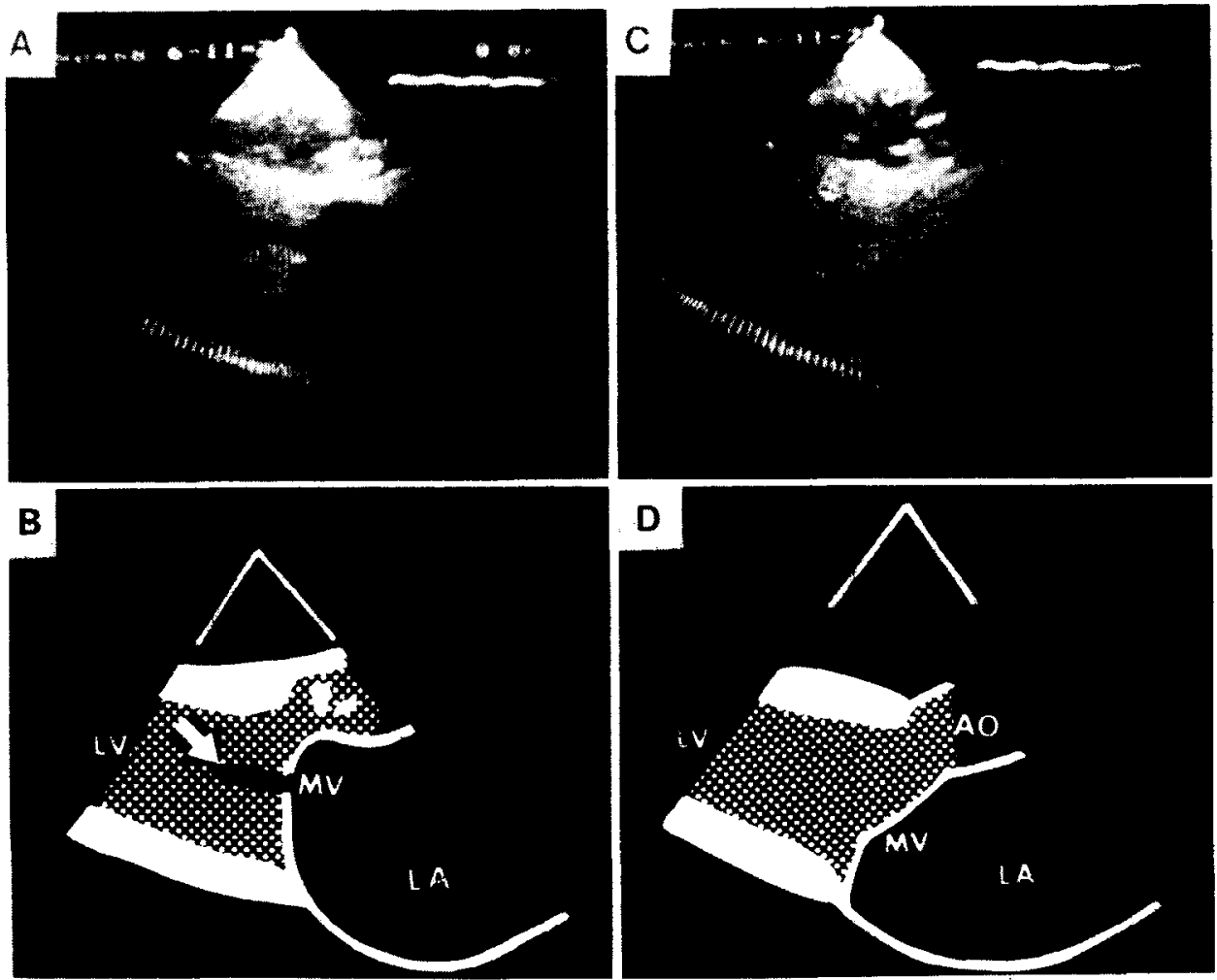

Figure 2. Stop frame images (above) and diagrams (below) from an echocardiographic left ventriculogram obtained during an injection of 5 cc of 5 percent dextrose in water by hand. $\mathbf{A}$ and $\mathbf{B}$, diastole. $\boldsymbol{C}$ and $\mathbf{D}$, systole. Note opacification of the left ventricle (shaded areas in $B$ and D). A jet of negative contrast material (unopacified blood) enters the left ventricle from the left atrium in diastole (arrow, panel B). The catheter tip across the aortic valve in the left ventricle is not imaged. Note absence of mitral regurgitation during systole. $L V=$ left ventricle; $M V=$ mitral valve; $L A=$ left atrium; Ao $=$ aorta.

advantage in her management. Certainly heavy abdominal shielding and coning of the fluoroscopic ports with rare use of $x$-ray energy can minimize the exposure of the fetus to ionizing radiation, but its entire absence without any loss of diagnostic information is preferable.
A further advantage of echocatheterization is that the contrast media of 5 to $10 \mathrm{cc}$ of 5 percent dextrose in water requires no power injector and has no known cardiac or systemic toxicity. The injections cause no premature contractions, improving the ability to judge
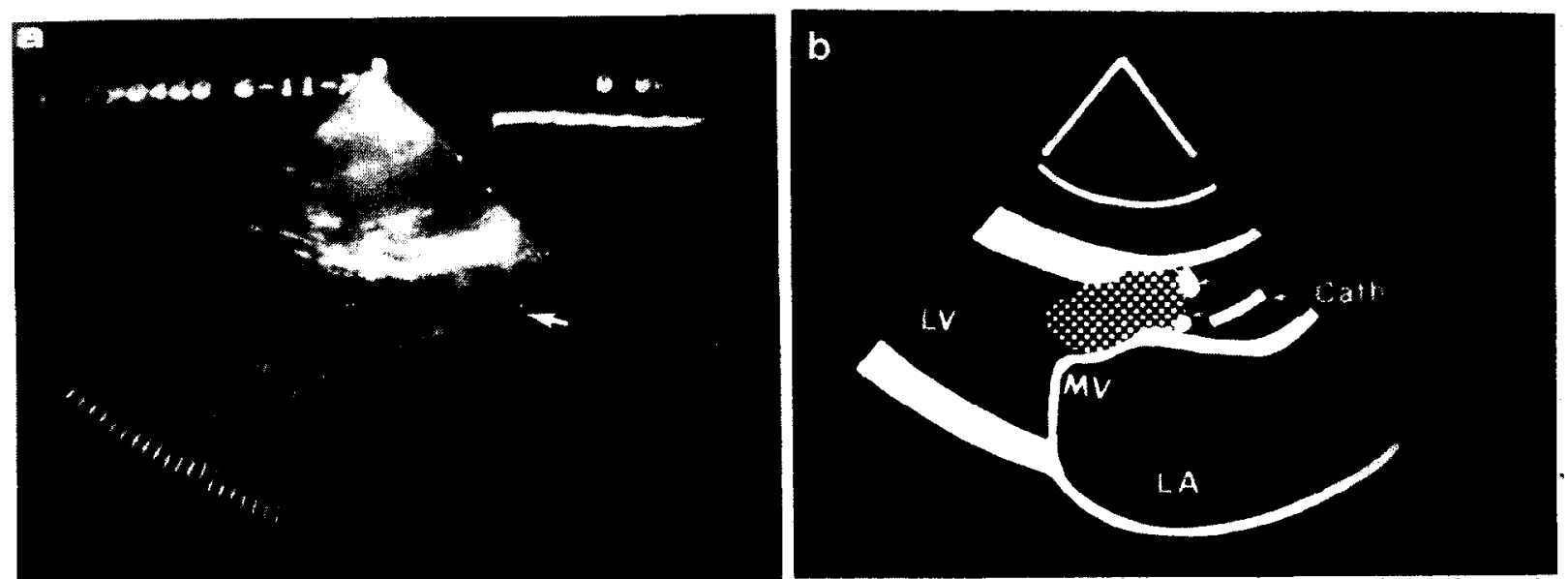

Figure 3. a, stop frame image from an echocardiographic supravalvular aortogram. $b$, diagram of panel a. Note the catheter in the aortic root (arrow, panel a; "Cath", panel b) and the opacification of the left ventricular outflow trace (shaded area, panel b) indicating aortic regurgitation. Contrast was obtained with an injection of 5 percent dextrose in water by hand. Abbreviations same as in Figure 1. 
regurgitation and contraction patterns. They can be repeated many times in different views without deleterious effects. The relative ease with which the stenotic aortic valve was crossed in this patient suggests that echocatheterization may be useful as an adjunct to or even as a superior substitute for fluoroscopy when guiding a retrograde left ventricular catheter through stenotic aortic valves. However, since this was not a controlled study, the contribution of echocardiography to the crossing of the aortic valve is uncertain. The catheter, aortic root and aortic valve leaflets could be continuously visualized during the probing procedure (Figure 1). When the aortic leaflets are not calcified, only the catheter is imaged by fluoroscopy during probing. Switching fluoroscopic views to determine whether the catheter is too anterior or posterior involves table, $\mathrm{C}$-arm or patient rotation. In contrast, we only needed to rotate the echocardiographic transducer to change views of the aortic root from a long to a short axis to obtain this information.

Some limitations of the echocatheterization technique should be mentioned. Two-dimensional echocardiograms can be of poor quality, so diagnostic information is not available in some patients. Presently, information about coronary arteries can only be obtained with standard coronary arteriography. When a catheter "tip" seems to be imaged in a two-dimensional echocardiographic tomographic plane, the clinician is not sure whether this is the true tip or rather the point at which the catheter leaves the plane of imaging. It is even possible that a strongly reflective object such as a catheter might be "falsely" imaged due to lateral resolution artifacts despite being entirely outside the plane of imaging [5]. Conversely, catheters may not always be detected [6]. Even in the nondilated aortic root in our patient, the catheter tip sometimes left the plane of imaging during manipulation. This may be partly a training problem that will occur less frequently with an experienced operator.

The technique of echocatheterization obviously needs to be perfected, but the conclusion appears warrented that two-dimensional echocardiography may be an adequate method to guide an entire catheterization. It can easily be used in conjunction with fluoroscopy and, in selected instances, may offer certain advantages over fluoroscopy. Application of this technique in patients with valve disease when coronary arteriography is not planned could significantly reduce operator as well as patient exposure to radiation.

\section{ACKNOWLEDGMENT}

We wish to thank Willem Gorissen for technical help, Colette Meltzer for aid in illustration preparation, and Ellen Verheul and Inge van Balen for assistance in manuscript preparation.

\section{REFERENCES}

1. Brill $A B$, Nance WE: Radiation. Induced abnormalities in human development. In: Marcus SL, Marcus CC eds. Advances in obstetrics and gynecology, chap. 5. Baltimore: Williams \& Wilkins 1967: 573-583.

2. Metcalf $J$, Ueland $K$ : The heart and pregnancy. In: Hurst JW, et al. eds. The heart. 4th ed. New York: McGraw-Hill 1978: 1721-1734.

3. Laird-Meeter K, van de Ley D, Bom N, Wladimiroff JW, Roelandt $\mathrm{J}$ : Circulatory adjustments during pregnancy: an echocardiographic study. Clin Cardiol 1979; 2: 328-332.
4. Grandjean T: Le microcathétérisme cardiaque gauche, practible au lit du malade à l'aide d'une méthode de repérage par électrocardioscopie endo-aortique continu. Arch Mal Coeur 1972; 65: 1335-1341.

5. Roelandt J, van Dorp WG, Bom N, Laird-Meeter K, Hugenholtz PG: Resolution problems in echocardiology: a source of interpretation errors. Am J Cardiol 1976; 37: 255-262.

6. Reeves WC, Nanda NC, Barold S: Echocardiographic evaluation of intracardiac pacing catheters: M-mode and two-dimensional studies. Circulation 1978; 58: 1049-1056. 